\title{
Reflexos jurídicos da Resolução CFM 1.995/12
}

Luciana Dadalto $^{1}$

\section{Resumo}

O presente artigo de pesquisa tem como objetivo verificar os reflexos jurídicos da Resolução 1.995/12 do Conselho Federal de Medicina. Para tanto, faz uma análise das diretivas antecipadas no mundo, intentando entender o instituto e, posteriormente, analisar como esta resolução reflete na área jurídica, concluindo, por fim, pela necessidade de legislação específica sobre o tema no Brasil.

Palavras-chave: Diretivas antecipadas. Legislação como assunto. Regulamentos.

\section{Resumen}

\section{Reflejos jurídicos de la Resolución CFM 1.995/12}

Este artículo de investigación tiene por objeto comprobar las consecuencias jurídicas de la Resolución 1.995/12 del Conselho Federal de Medicina (Consejo Federal de Medicina). Para tanto, hace un análisis de las instrucciones previas en el mundo, con el fin de comprender el instituto y, más adelante, analizar cómo esta resolución refleja en el ámbito jurídico, concluyendo, por fin, por la necesidad de una legislación específica acerca del tema en Brasil.

Palabras-chave: Directivas anticipadas. Legislación como asunto. Reglamentos.

\section{Abstract \\ Legal repercussions of the Resolution CFM 1.995/12}

This research article aims to verify the juridical consequences of Resolution 1.995/12 of the Conselho Federal de Medicina (Federal Council of Medicine). In order to understand the institute, an analysis of advance directives in the world is done, later, analyze how this resolution reflects in the legal world, concluding, by the necessity to legislate about the theme in Brazil.

Key words: Advance directives. Legislation as a topic. Regulations.

1. Doutoranda lucianadadalto@uol.com.br - Faculdade de Medicina da Universidade Federal de Minas Gerais (UFMG), Belo Horizonte/ MG, Brasil.

\section{Correspondência}

Rua Teixeira de Freitas, 336, apt 702 Santo Antônio CEP 30350-180. Belo Horizonte/MG, Brasil.

Declara não haver conflito de interesse. 
Este artigo decorre de pesquisa realizada mediante revisão da literatura acerca da regulamentação das diretivas antecipadas em países que já legislaram sobre tal instituto, bem como de literatura jurídica e bioética específica sobre temas afetos às diretivas antecipadas como a capacidade, a suspensão de nutrição e hidratação e a formalização de manifestação de vontade.

As diretivas antecipadas (advanced care documents), tradicionalmente, têm sido entendidas como o gênero do qual são espécies o testamento vital (living will) e o mandato duradouro (durable power attorney). Ambos os documentos serão utilizados quando o paciente não puder se expressar, livre e conscientemente - ainda que por uma situação transitória -, ou seja, as diretivas antecipadas, como gênero, não se referem exclusivamente a situações de terminalidade. Enquanto o testamento vital refere-se a instruções acerca de futuros cuidados médicos ao quais uma pessoa que esteja incapaz de expressar sua vontade será submetida, ante um diagnóstico de terminalidade da vida, o mandato duradouro refere-se a simples nomeação de um terceiro para tomar decisões em nome do paciente quando este estiver impossibilitado - definitiva ou temporariamente - de manifestar sua vontade ${ }^{1}$.

As diretivas antecipadas fundamentam-se nos princípios da autonomia, do respeito às pessoas e da lealdade e possuem como benefício a melhoria da relação médico-paciente, e a autoestima do paciente. Também, sem dúvida, propicia a diminuição de sentimentos de culpa e indecisão nos parentes ${ }^{2}$.

O mandato duradouro é o documento no qual o paciente nomeia um ou mais procuradores que devem ser consultados pelos médicos no caso de incapacidade temporária ou definitiva para tomar alguma decisão sobre tratamento ou procedimento quando não houver manifestação prévia de vontade ou, em havendo, se nesta há lacuna obscura que impeça a plena compreensão por parte de quem atende ao paciente. Saliente-se que o procurador de saúde decidirá com base na vontade do paciente ${ }^{1}$.

Segundo os modelos de autonomia apontados por Beuchamp e Childress é possível inferir que o mandato duradouro enquadra-se no modelo de julgamento substituto, no qual é necessário que $a$ intimidade do decisor substituto com o paciente seja suficientemente profunda e relevante para que o julgamento reflita os objetivos e as opiniões do paciente ${ }^{3}$. Em contrapartida, o testamento vital é um documento no qual uma pessoa capaz possa indicar seu desejo de que se deixe de lhe aplicar um trata- mento em caso de enfermidade terminal ${ }^{4}$. Este documento enquadra-se no modelo denominado por Beuchamp e Childress ${ }^{5}$ como de pura autonomia, vez que neste há expressa manifestação de vontade do paciente, feita enquanto capaz.

A coexistência do mandato duradouro e do testamento vital em um único documento é possível e salutar para o paciente, contudo, como a aplicabilidade do mandato duradouro não se restringe a situações de terminalidade da vida, para o procurador seria interessante que se fizesse um testamento vital contendo a nomeação de um procurador (mandato duradouro) e, concomitantemente, um mandato duradouro nomeando o mesmo procurador para que não haja conflito entre os documentos - , a fim de que este possa agir em situações que não envolvam terminalidade.

\section{Contexto mundial}

As diretivas antecipadas de vontade surgiram nos Estados Unidos da América (EUA) na década de 60 . Em verdade, primeiramente a espécie mais utilizada, o testamento vital, proposto pela primeira vez em 1967 pela Sociedade Americana para a Eutanásia como um documento de cuidados antecipados, pelo qual o indivíduo poderia registrar seu desejo de interromper as invenções médicas de manutenção da vida ${ }^{6}$

Em 1969, um modelo de declaração prévia de vontade do paciente terminal foi proposto pelo advogado Louis Kutner, que, segundo Urionabarrenetxea ${ }^{7}$, era tido como um meio de solução de conflitos entre médicos, pacientes terminais e familiares acerca da tomada de decisão dos tratamentos a que o paciente em estado de terminalidade deveria ser submetido. Em 1976, o Estado da Califórnia aprovou o Natural Death Act, elaborado pela Faculdade de Direito da Universidade de Yale - lei que se tornou o primeiro diploma legal a textualmente reconhecer o testamento vital.

A partir da aprovação da lei californiana, vários estados norte-americanos aprovaram leis regulamentando o testamento vital. Mas o caso Nancy Cruzan - cujos pais solicitaram a retirada dos aparelhos que a mantinham viva pois estava em coma permanente e irreversível após um acidente automobilístico, alegando que a mesma havia manifestado, em conversa com uma amiga tempos antes do acidente, que não gostaria de ser mantida viva quando tivesse menos da metade de suas capacidades normais -, que chegou à Suprema Corte 
estadunidense em 1990, a qual deferiu o pedido, ordenando ao hospital que cumprisse a vontade da família da paciente, foi decisivo para a feitura de uma lei acerca do tema nos EUA. Assim, sob forte clamor público, em 1991 foi aprovada a Patient SelfDetermination Act (PSDA) ${ }^{8}$, a primeira lei federal a reconhecer o direito à autodeterminação do paciente e o direito do paciente a fazer uma diretiva antecipada, em suas duas modalidades: testamento vital e mandato duradouro.

Na realidade, as legislações estaduais já faziam clara confusão entre as duas espécies e tal fato em muito contribuiu para que esse imbróglio prevaleça até hoje - o que será visto neste artigo. 0 primeiro país europeu a legalizar as diretivas antecipadas foi a Espanha, que em 2002 promulgou a lei 419. Saliente-se, contudo, que a legislação espanhola rechaçou a terminologia estadunidense diretivas antecipadas por julgá-la alijada do mundo da bioética e do direito sanitário, assim, na Espanha, este instituto é denominado instrucciones previas.

Ocorre que, não obstante a legislação espanhola ter sido promulgada mais de dez anos após a legislação estadunidense, as discussões naquele país tiveram início em 1986 com a Associación Pro Derecho a Morir Dignamente, que, naquele ano, redigiu um modelo de testamento vital. Destaque-se, entretanto, que a primeira província espanhola a legislar o tema foi a catalã, na Lei $21 / 00{ }^{10}$, de 19 de dezembro, em seu artigo $8^{\circ}$. Após essa publicação, comunidades autônomas como Galícia, Extremadura, Madrid, Aragón, La Rioja, Navarra e Catambria também regularam o tema ${ }^{11-17}$. Acompanhando essa tendência, a Espanha sancionou a lei dispondo sobre as instrucciones previas em 2002.

Em linhas gerais, as instruções prévias na Espanha devem conter orientações à equipe médica sobre o desejo de que não se prolongue artificialmente a vida, a não utilização dos chamados tratamentos extraordinários, a suspensão do esforço terapêutico e a utilização de medicamentos para diminuir a dor, entre outras. A Lei $41 / 02{ }^{9}$ possibilita que no documento de instruções prévias o outorgante nomeie um representante para que, quando aquele estiver impossibilitado de manifestar sua vontade, este terceiro possa fazê-lo em nome do subscritor do documento. Ou seja, a lei espanhola apresenta uma verdadeira diretiva antecipada, com a possibilidade de conter, em um único documento, o testamento vital e o mandato duradouro.

Em 2 de fevereiro de 2007, foi publicado o Real Decreto $124 / 07{ }^{18}$, instrumento que regula o ponto 5 deste artigo, pois cria o Registro Nacional de
Instrucciones Previas e o correspondente arquivo automatizado de dados de caráter pessoal. Segundo o decreto, o acesso a esse Registro Nacional é restrito às pessoas que fizeram as instruções prévias, aos representantes legais dessas pessoas ou a quem o outorgante tenha designado neste documento, aos responsáveis dos registros autônomos e às pessoas designadas pela autoridade sanitária da comunidade autônoma correspondente ou pelo Ministerio de Sanidad y Consumo.

Em Portugal, a discussão começou em 2006, com o projeto de lei de autoria da Associação Portuguesa de Bioética, mas apenas em julho de 2012 foi promulgada a lei que regulamenta as diretivas antecipadas de vontade ${ }^{19}$, com algumas alterações ao texto original. Esta lei contém clara confusão terminológica, vez que iguala o testamento vital às diretivas antecipadas de vontade e trata o mandato duradouro, lá chamado de procurador para cuidados em saúde, como outro instituto jurídico - mas prevê a criação de um registro nacional, o que significa grande avanço na operacionalização deste instituto.

Na Argentina, a primeira legislação sobre diretivas antecipadas foi a Lei 4.263, da província de Rio Negro, promulgada em 19 de dezembro de 2007. Em 2009 , foi promulgada a lei federal $26.529^{20}$, sobre os direitos do paciente, que no artigo 11 reconhece o direito de o paciente dispor sobre suas vontades por meio de diretivas antecipadas. Todavia, esta lei não traz maiores detalhes sobre o tema.

\section{Resolução CFM 1.995/12}

No dia 31 de agosto de 2012 o Conselho Federal de Medicina (CFM) aprovou a Resolução $1.995{ }^{21}$, dispondo sobre diretivas antecipadas de vontade. Esta é a primeira regulamentação sobre a matéria no país, com a qual o CFM segue a tradição de se posicionar sobre temas bioéticos antes do Poder Legislativo. Em observância técnica à historicidade do instituto, o CFM optou por reconhecer, em um mesmo documento, o testamento vital e o mandato duradouro, fato não compreendido pela imprensa brasileira - que frequentemente tem se referido à aprovação do testamento vital pelo Conselho.

Interessante notar que a resolução refere-se, em seus "considerandos", ao paciente em estado terminal e na exposição de motivos, aos pacientes em fim de vida. Ocorre que essas duas expressões não são sinônimas e podem gerar confusão na feitura e na aplicação das diretivas antecipadas. Isto por- 
que paciente terminal é aquele cuja condição é irreversivel, independente de ser tratado ou não, e que apresenta uma alta probabilidade de morrer num período relativamente curto de tempo ${ }^{22}$. Por sua vez, os pacientes em fim de vida podem ser entendidos como os terminais e, também, como aqueles que estão em estado de coma profundo e irreversível, ou ainda em estado vegetativo persistente (EVP).

Como o CFM expressou em nota esclarecedora, a Resolução 1.995 respeita a vontade do paciente conforme o conceito de ortotanásia e não possui qualquer relação com a prática de eutanásia. Em verdade, este esclarecimento apenas reafirmou o conceito basilar das diretivas antecipadas: não podem conter disposições contrárias ao ordenamento jurídico do país em que são propostas. Logo, como a eutanásia é proibida no Brasil e a ortotanásia é permitida, conforme entendimento judicial no julgamento da ação civil pública 2.007.34.00.014809-3 ${ }^{23}$, a resolução - logicamente - acata esta determinação. O que a resolução efetivamente fez foi reconhecer o direito de o paciente recusar tratamentos fúteis, também conhecidos como extraordinários, entendidos como os tratamentos que não oferecem benefício real ao paciente, pois a morte é inevitável ${ }^{3}$, ou seja, são aqueles tratamentos que visam apenas prolongar a vida biológica do paciente, sem garantir a qualidade de vida.

\section{Implicações jurídicas da resolução}

Muito se questiona sobre os efeitos jurídicos da Resolução CFM 1.995/12. Primeiramente, é preciso ressaltar que esta resolução, como as demais do CFM, tem força de lei entre a classe médica, ou seja, se não se pode afirmar que as diretivas antecipadas de vontade estejam legalizadas no Brasil, é preciso reconhecer que se constitui grande passo na discussão sobre o tema no país. Há pouco mais de um ano, essa discussão ainda era incipiente, existiam apenas artigos científicos de periódicos de bioética que tratavam a temática de maneira abrangente ${ }^{24-27}$ e um livro específico sobre o tema ${ }^{28}$. Poucas eram as notícias de registros de diretivas antecipadas nos cartórios brasileiros, número que tem crescido exponencialmente ${ }^{29}$.

Hoje, faz-se necessário regulamentar as diretivas antecipadas por lei, pois o CFM não possui competência legal para regulamentar pontos importantes e necessários, a seguir apresentados.
Quais sujeitos podem fazer diretivas antecipadas

A imprensa divulgou que apenas os maiores de 18 anos e os menores emancipados podem recorrer às diretivas antecipadas; contudo, é possível que uma legislação específica estabeleça que os relativamente incapazes (maiores de 16 anos) também podem fazê-la.

No concreto, o necessário na feitura das diretivas antecipadas é o discernimento do outorgante, haja vista que a capacidade é gênero do qual são espécies a capacidade de direito e a de fato. A primeira refere-se à aquisição de direitos e deveres; a segunda, ao exercício destes, de modo que a capacidade de direito é inerente ao ser humano, conforme se depreende do art. $1^{\circ}$ do Código Civil de $2002{ }^{30}$, e a capacidade de fato depende do discernimento. Assim, o regime das incapacidades foi concebido como sistema que busca proteger aqueles sujeitos que não têm discernimento suficiente para formare exprimir vontade válida ${ }^{31}$.

Ocorre que no âmbito das situações jurídicas que envolvam médicos e pacientes, capacidade de fato não é, sempre, sinônimo de discernimento, pois é possível que um paciente seja civilmente capaz, mas o médico constate que o mesmo está utilizando medicamentos que afetem suas faculdades mentais ou, ainda, que a doença esteja afetando sua possibilidade de fazer escolhas autônomas. Ou seja, na verdade, está-se questionando a capacidade de o paciente tomar uma decisão e entender as informações prestadas pelo médico, e não a capacidade deste moldada ao Código Civil de $2002^{30}$.

Assim, a capacidade, entendida como discernimento, é requisito essencial para a validade do consentimento prestado. Contudo, a capacidade civil é mera formalidade, não devendo ser levada em conta para aferir a validade do consentimento informado do paciente, pois, no caso concreto, deve-se verificar se à época da manifestação do consentimento o paciente estava em pleno gozo de suas funções cognitivas e não se este se enquadrava no conceito de pessoa capaz civilmente. Significa dizer que os limites objetivos de fixação de idade utilizados pelo Código Civil devem ser flexibilizados, vez que a declaração de incapacidade não pode, de maneira apriorística, comprometer integralmente a autonomia privada conferida pelo ordenamento jurídico ao ser humano, ainda que acometido de enfermidade ou deficiência física ou mental que afete seu discernimento ${ }^{31}$ - portanto, caso um menor de idade queira redigir uma diretiva antecipada, deverá primeiramente requerer autorização judicial, 
que somente poderá negá-la se for comprovada a falta de discernimento deste para praticar tal ato.

\section{Especificação dos tratamentos que podem ser acei- tos ou recusados}

A mera informação de que o paciente pode recusar tratamentos extraordinários não é satisfatória sob o ponto de vista da praticidade do instituto. Isto porque existem pontos polêmicos sobre a classificação de certos tratamentos ou procedimentos como cuidados paliativos ou tratamentos extraordinários, especialmente a suspensão de hidratação e nutrição.

Existem quatro princípios que orientam os cuidados paliativos. O primeiro é o da proporcionalidade terapêutica, segundo o qual há uma obrigação moral de se implementar todas as medidas terapêuticas que tenham proporção entre os meios empregados e o resultado previsível; o segundo, é o do duplo efeito, que dispõe acerca da necessidade de se averiguar a razão proporcional entre os tratamentos que tenham duplo efeito; o terceiro, é o da prevenção, em que se deve prever possíveis complicações e sintomas que frequentemente se apresentam a portadores de determinada doença; o quarto, e último, é o do não abandono e do tratamento da dor, segundo o qual o médico não pode abandonar o paciente, exceto em casos de objeção de consciência, e deve controlar a dor.

Deste modo, qualquer tratamento ou procedimento que não esteja orientado por estes princípios pode ser considerado extraordinário e, portanto, passível de ser recusado pelo paciente, até mesmo a hidratação e nutrição, pois restou provado em vários estudos ${ }^{32,33}$ que em casos extremos o organismo do paciente não absorve mais nutrientes e a nutrição e hidratação podem, até mesmo, causar desconforto. Logo, é imperioso que nova resolução do CFM e até mesmo uma legislação federal aclarem essa situação.

Ademais, o Direito Comparado nos apresenta que no conteúdo das diretivas antecipadas tem sido aceita a disposição sobre doação de órgãos. Mas a doação de órgãos no Brasil já está regulada pela Lei 9.434/97 ${ }^{34}$, alterada pela Lei $10.211 / 01{ }^{35}$, bastando que, para a efetivação da doação, seus ditames sejam seguidos. Entre eles, a autorização do cônjuge ou de parente maior de idade, obedecida a linha sucessória, o que não seria admissível nas diretivas antecipadas, vez que expressa a vontade autônoma do paciente.

\section{Obrigatoriedade do registro em cartório de notas e criação de Registro Nacional \\ O CFM, como órgão de classe, não tem compe-} tência para determinar que as diretivas antecipadas de vontade sejam, obrigatoriamente, registradas em cartório. Contudo, essa formalidade se faz imperiosa para garantir ao declarante que sua vontade será seguida. Em outras palavras, a lavratura de escritura pública das diretivas antecipadas garante a segurança jurídica.

A criação de um Registro Nacional de Diretivas Antecipadas também é recomendada, para possibilitar maior efetividade no cumprimento da vontade do paciente, de modo a não correr o risco de que a declaração se torne inócua. Assim, existindo tais disposições formais, o cartório deverá encaminhar as diretivas antecipadas ao Registro Nacional, em prazo exíguo, visando garantir sua efetividade. Esse procedimento poderá seguir as recomendações do Registro Central de Testamentos, do Colégio Notarial do Brasil, seção de São Paulo, dispostas no provimento CG 6/94 (Anexo G) ${ }^{36}$, que objetiva implantar um registro único de testamentos em São Paulo modelo que se tem estendido para outros estados do Brasil, como Minas Gerais, no qual o registro único ainda está em fase de implantação.

\section{Acompanhamento de um médico na feitura das di- retivas antecipadas}

A Resolução CFM 1.995/12 estabelece, no parágrafo segundo do artigo segundo, que o médico registrará, no prontuário, as diretivas antecipadas de vontade que Ihes foram diretamente comunicadas pelo paciente ${ }^{21}$. Ou seja, o CFM regulamentou que o papel dos médicos é apenas registrar no prontuário os desejos do paciente.

Contudo, o papel do profissional vai bem além da transcrição da vontade do paciente. A ele cabe não apenas transcrever as diretivas antecipadas, mas, como técnico, auxiliar o declarante quanto aos tratamentos e procedimentos que podem ou não ser recusados. Sendo assim, entende-se como imprescindível a orientação do médico de família do declarante para a realização das diretivas antecipadas. In- 
clusive, essa orientação é garantidora de que o conteúdo das diretivas antecipadas realmente expressa a real vontade do paciente, bem como observa os ditames do Código de Ética Médica. Enfim, a postura do médico deve ser ativa na feitura das diretivas antecipadas.

\section{Considerações finais}

A Resolução CFM 1.995/12 representa, sem dúvidas, grande avanço nas discussões acerca das diretivas antecipadas no Brasil. Contudo, o avanço ocorre em uma perspectiva localizada, pois se cinge ao âmbito médico e dos demais profissionais de saúde estudiosos do tema. É preciso, porém, ter em mente que a resolução não esgota o tema, pelo contrário, demonstra a necessidade de legislação específica sobre as diretivas antecipadas de vontade a fim de regulamentar questões afetas ao discernimento do outorgante, a uma exemplificação de cuidados e tratamentos que podem ou não ser recusados, aos critérios para aceitação e recusa dos mesmos, ao registro das diretivas antecipadas e à extensão da participação do médico da feitura das diretivas.

\section{Referências}

1. Sánchez CL. Testamento vital y voluntad del paciente: conforme a la Ley $n^{\circ} 41 / 2002$, de 14 de noviembre. Madrid: Dykinson; 2003. p. 27-8.

2. Gonzáles MAS. O novo testamento: testamentos vitais e diretivas antecipadas. In: Bastos EF, Sousa AH. Família e jurisdição. Belo Horizonte: Del Rey; 2006. p. 91-137.

3. Beauchamp TL, Childress JF. Princípios de ética biomédica. São Paulo: Loyola; 2002. p. 197.

4. Betancor JT. Testamento vital. Cuaderno del Instituto Vasco de Criminología. 1995;9:98.

5. Beauchamp TL, Childress JF. Op.cit. p. 199-204.

6. Emanuel EJ, Emanuel LL. Living wills: past, present, and future. J Clin Ethics. 1990;1(1):1-19. p. 10.

7. Urionabarrenetxea KM. Reflexiones sobre el testamento vital (I). Aten Primaria. 2003;319(1):52-4.

8. University of California. California natural death act: medical staff conference. West J Med. 1978;128:318-30.

9. Espanha. Ley $n^{\circ} 41 / 2002$, de 14 de noviembre. Básica reguladora de la autonomía del paciente y de derechos y obligaciones en materia de información y documentación clínica. Boletín Oficial del Estado. [internet]. 15 nov. 2002 [acesso 3 nov. 2012]. Disponível: http://www.boe.es/buscar/ doc.php?id=BOE-A-2002-22188

10. Catalunha. Lei $n^{\circ} 21 / 2000$, de 19 de dezembro. Sobre los derechos de información concernientes a la salud y la autonomía del paciente, y la documentación clínica. Boletin Oficial de Cataluña. [internet]. 29 dez. 2000 [acesso 3 nov. 2012]. Disponível: http://legislacion.derecho.com/ley21-2000-sobre-los-derechos-de-informacion-concernientes-a-la-salud-y-la-autonomia-delpaciente-y-la-documentacion-clinica

11. Galícia. Ley $n^{\circ} 3 / 2001$, de 28 de mayo. Reguladora del consentimiento informado y de la historia clínica de los pacientes. Boletín Oficial del Estado. [internet]. 3 jul. 2001 [acesso nov. 2012]. Disponível:http://www.boe.es/boe/dias/2001/07/03/pdfs/A23537-23541.pdf

12. Extremadura. Ley $n^{\circ} 3 / 2005$, de 8 de julio. Información sanitaria y autonomía del paciente. Boletín Oficial del Estado. [internet]. 5 ago. 2005 [acesso 3 nov. 2012]. Disponível: http://legislacion. derecho.com/ley-3-2005-de-informacion-sanitaria-y-autonomia-del-paciente

13. Madrid. Ley $n^{\circ} 3 / 2005$, de 23 de mayo. Por la que se regula el ejercicio del derecho a formular Instrucciones Previas en el ámbito sanitario y se crea el registro correspondiente. Boletín Oficial del Estado. [internet]. 10 nov. 2005 [acesso 3 nov. 2012]. Disponível: http://legislacion.derecho. com/ley-3-2005-por-la-que-se-regula-el-ejercicio-del-derecho-a-formular-instrucciones-previasen-el-ambito-sanitario-y-se-crea-el-registro-correspondiente

14. Aragón. Ley $n^{\circ} 6 / 2002$, de 15 de abril. De Salud de Aragón. Boletim Oficial de Aragon. [internet]. 28 de maio 2003[acesso 3 nov. 2012];(64). Disponível: http://www.aragon.es/ estaticos/GobiernoAragon/Departamentos/SaludConsumo/Profesionales/01_Legislacion/01_ Recopilacion_Tematica/Decreto_100-2003.pdf

15. La Rioja. Ley $n^{\circ} 9 / 2005$, de 30 de septiembre. Reguladora del documento de instrucciones previas en el ámbito de la sanidad. Boletín Oficial del Estado. [internet]. 21 out. 2005 [acesso 3 nov. 2012]. Disponível:: http://www.boe.es/boe/dias/2005/10/21/pdfs/A34392-34395.pdf

16. Navarra. Ley $n^{\circ}$ Foral $11 / 2002$, de 6 de mayo, sobre los derechos del paciente a las voluntades anticipadas, a la información y a la documentación clínica. Boletín Oficial del Estado. [internet]. 30 de maio 2002 [acesso 3 nov. 2012]. Disponível: http://www.boe.es/boe/dias/2002/05/30/ pdfs/A19249-19253.pdf 
17. Cantabria. Decreto ${ }^{\circ} 139 / 2004$, de 5 de diciembre. Crea y regula el Registro de Voluntades Previas de Cantabria. Boletín Oficial de Cantabria. [internet]. 27 dez. 2004 [acesso 3 nov. 2012]:12419. Disponível: http://boc.cantabria.es/boces/verAnuncioAction.do?idAnuBlob=75015

18. Espanha. Real Decreto $n^{\circ} 124$, de 2 de febrero de 2007. Regula o punto 5 de esto artículo y cría el Registro Nacional de Instrucciones Previas apud Blanco JZ. Autonomía e instrucciones previas: un análisis comparativo de las legislaciones autonómicas del Estado Español. [tese]. [internet]. Catalunha: Universidad de Catabria; 2007 [acesso 3 nov. 2012]. Disponível: http:// www.tesisenred.net/bitstream/handle/10803/10650/TesisJZB.pdf?sequence=1

19. Portugal. Lei $n^{\circ} 25 / 2012$, de 16 de junho. Regula as diretivas antecipadas de vontade, designadamente sob a forma de testamento vital, e a nomeação de procurador de cuidados de saúde e cria o Registro Nacional do Testamento Vital (Rentev). Diário da República.

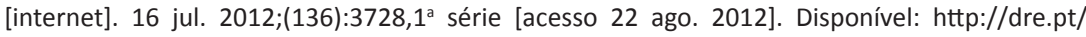
pdf1sdip/2012/07/13600/0372803730.pdf

20. Argentina. Ley $n^{\circ} 26.529$, de 21 de octubre de 2009. Derechos del paciente en su relación con los profesionales e instituciones de la salud. 19 nov. 2009 [acesso 31 ago. 2009]. Disponível: http:// www.sssalud.gov.ar/novedades/archivosGSB/documentos/ley_26529_pen.pdf

21. Conselho Federal de Medicina. Resolução $n^{\circ} 1.995$, de 9 de agosto de 2012. Dispõe sobre as diretivas antecipadas de vontade dos pacientes. [internet]. 31 ago. 2012 [acesso 31 ago. 2012]. Disponível: http://www.portalmedico.org.br/resolucoes/CFM/2012/1995_2012.pdf

22. Knobel M, Silva ALM. O paciente terminal: vale a pena investir no tratamento? Revista Einstein. 2004;2:133.

23. Justiça Federal do Distrito Federal. Processo $n^{\circ}$ 2.007.34.00.014809-3. Trata-se de ação civil pública com pedido de antecipação de tutela ajuizada pelo Ministério Público Federal contra o Conselho Federal de Medicina pleiteando o reconhecimento da nulidade da Resolução CFM n ${ }^{\circ}$ $1.805 / 2006$ e alternativamente sua alteração a fim de que se definam critérios a serem seguidos para a prática da ortotanásia. [internet]. $1^{\circ}$ out. 2012 [acesso 31 ago. 2012]. Disponível: www.jfdf. jus.br/destaques/14\%20VARA_01\%2012\%202010.pdf

24. Vasconcelos TJQ, Imamura NR, Villar HCEC. Impacto da Resolução CFM n 1.805/06 sobre os médicos que lidam com a morte. Rev bioét (Impr.). 2011;19(2):501-21.

25. Feio AGO, Oliveira CC. Responsabilidade e tecnologia: a questão da distanásia. Rev bioét (Impr.). 2011;19(3):615-30.

26. Santos OM. Sofrimento e dor em cuidados paliativos. Rev bioét (Impr.). 2011;19(3):683-95.

27. Stolz C, Gehlen G, Bonamico EL, Bortoluzzi MC. Manifestação das vontades antecipadas do paciente como fator inibidor da distanásia. Rev bioét (Impr.). 2011;19(3):833-45.

28. Dadalto L. Testamento vital. Rio de Janeiro: Lumen Júris; 2010.

29. Mariz R. O direito de morrer: a hora do adeus. Correio Braziliense. 25 abr. 2012;Caderno bem estar:57.

30. Brasil. Lei $n^{\circ} 10.406$, de 10 de janeiro de 2002. Código Civil. [internet]. [acesso 3 nov. 2012]. Disponível: http://www.planalto.gov.br/ccivil_03/Leis/2002/L10406.htm

31. Rodrigues RL. Incapacidade, curatela e autonomia privada: estudos no marco do estado democrático de direito [dissertação]. Belo Horizonte: Pontifícia Universidade Católica de Minas Gerais; 2005.

32. Gavicagogeascoa, MI. Futilidade terapêutica. In: Urban CA. Bioética clínica. Rio de Janeiro: Revinter; 2003. p. 522.

33. Campos ACL, Matias JEF. Nutrição no paciente terminal. In: Urban CA. Bioética clínica. Rio de Janeiro: Revinter; 2003. p. 504.

34. Brasil. Lei n ${ }^{\circ}$ 9.434, de 4 de fevereiro de 1997. Dispõe sobre a remoção de órgãos, tecidos e partes do corpo humano para fins de transplante e tratamento e dá outras providências. [internet]. [acesso 3 nov. 2012]. Disponível: http://www.planalto.gov.br/ccivil_03/Leis/L9434.htm

35. Brasil. Lei $n^{\circ} 10.211$, de 23 de março de 2001. Altera dispositivos da Lei $n^{\circ} 9.434$, de 4 de fevereiro de 1997, que "dispõe sobre a remoção de órgãos, tecidos e partes do corpo humano para fins de transplante e tratamento". [internet]. [acesso 3 nov. 2012]. Disponível: http://www.planalto.gov. br/ccivil_03/Leis/LEIS_2001/L10211.htm

36. Colégio Notarial do Brasil. Seção São Paulo. Registro Central de Testamentos. Provimento CG 06, de 17 de maio de 1994. Instituído em todo o Estado de São Paulo Registro Central de Testamentos públicos. [internet]. [acesso 3 nov. 2012]. Disponível: http://www.cnbsp.org.br/print/info_rct_ provimento_0694.htm 